\title{
Character Education Management in Improving Education Quality in State Senior High School
}

\author{
Mulatul Aini ${ }^{1 凶}$, Rahmi Fitria \\ Manajemen Pendidikan Islam, Institut Agama Islam Negeri Batusangkar, Indonesia ${ }^{1,2}$ \\ email: mulatulaini394@gmail.com ${ }^{1}$, mpirahmifitria@gmail.com²
}

DOI: $10.31958 /$ iies.v1i2.2972

\begin{tabular}{ll}
\hline Article info & \multicolumn{1}{c}{ Abstract } \\
\hline Article History & This study aims to identify and explain the management of character education in \\
Recieved: & terms of planning, organizing, implementing, and monitoring in improving the \\
$04 / 03 / 2021$ & quality of education in State Senior High Schools (SMAN). This research was \\
Accepted: & descriptive qualitative. Sources of data in this study were principals, vice \\
$17 / 11 / 2021 \mathrm{~s}$ & principals, and teachers. Data collection techniques were observation, interviews, \\
Published: & and documentation, while data analysis techniques included data reduction, data \\
$30 / 11 / 2021$ & display, and conclusion drawing and verification. Based on data analysis, it was \\
& found that character education management is started from planning students \\
character education by determining the goals, constructing programs or school & activities, and integrating character values. Furthermore, the organization of \\
Corresponding author & character education is carried out by dividing the tasks and the person in charge \\
& of the activity or program. Next, the implementation of character education is \\
& through the integration of character values in all subjects, in the school daily \\
& activities, in school programs, as well as building communication and cooperation \\
& between schools and parents of students. Lastly, character education is done \\
& through supervision consists of observing students behavior and scoring \\
& mentioned in students'discipline book.
\end{tabular}

Keywords: Management of Character Education, Quality Of Education, Senior High School.

\begin{abstract}
Abstrak
Penelitian ini bertujuan untuk mengetahui dan menjelaskan manajemen pendidikan karakter baik perencanaan, pengorganisasian, pelaksanaan dan juga pengawasan dalam meningkatkan mutu pendidikan di Sekolah Menengah Atas Negeri (SMAN). Penelitian ini adalah deskriptif kualitatif. Sumber data pada penelitian ini adalah kepala sekolah, wakil kepala sekolah dan guru. Teknik pengumpulan data dalam penelitian menggunakan observasi, wawancara dan dokumentasi, sedangkan teknik analisis data meliputi reduksi data, penyajian data serta penarikan kesimpulan dan verifikasi. Hasil Penelitian yang diperoleh yaitu manajemen pendidikan karakter yang dijalankan dimulai dari perencanaan pendidikan karakter siswa dengan menentukan tujuan pendidikan karakter, menyusun program atau kegiatankegiatan sekolah, dan mengintegrasikan nilai-nilai karakter. Selanjutnya pengorganisasian pendidikan karakter dilaksanakan dengan pembagian tugas dan penanggung jawab kegiatan atau program. Selanjutnya pelaksanaan pendidikan karakter melalui pengintegrasian nilai-nilai karakter pada seluruh mata pelajaran, pengintegrasian nilai-nilai karakter dalam kegiatan sehari-hari sekolah. pengintegrasian nilai-nilai-nilai pada kegiatan yang diprogramkan oleh sekolah, serta membangun komunikasi dan kerja sama antara sekolah dan orang tua peserta
\end{abstract}


didik. Terakhir melalui pengawasan terdiri dari pengamatan perilaku peserta didik dan penskoran yang terdapat dalam buku tata tertib peserta didik.

Kata Kunci: Manajemen Pendidikan Karakter, Mutu Pendidikan, SMA

JIES is licensed under a Creative Commons Atribution-Share Alike 4.0 Internasional Licence

(c) 9 (9)

\section{PENDAHULUAN}

Pendidikan merupakan faktor utama pembentuk kepribadian manusia. Dengan pendidikan diharapkan akan lahir generasi penerus bangsa yang berkualitas dan mampu beradaptasi untuk hidup berbangsa dan bernegara (Tanis, 2013). Hasil penelitian yang dilakukan oleh Suwuh et al., (2017) menemukan bahwa pemerintah sangat serius dalam hubungannya dengan sektor pendidikan. Pendidikan memegang peranan yang sangat penting dalam meningkatkan kualitas sumber daya manusia dan berjuang untuk mewujudkan cita-cita bangsa Indonesia (Mualim \& Saputra, 2021; Zulhendri \& Warmansyah, 2020).

Pendidikan membantu membentuk karakter. Pendidikan budi pekerti memiliki peranan penting dalam pembentukan akhlak, dalam pendidikan atau pendidikan tidak sebatas transmisi atau pembekalan ilmu, tetapi yang terpenting adalah menjadi karakter dan kepribadian Anda untuk berperilaku lebih baik dalam kehidupan sehari-hari (Sajadi, 2019). Hasil penelitian yang dilakukan oleh Utami, (2019) menemukan bahwa Salah satunya adalah penerapan pendidikan karakter, karena dengan pendidikan karakter, manusia dapat berperilaku baik untuk hidup sesuai dengan kehidupan bermasyarakat, bernegara dan bernegara.

Salah satu pendiri negara dan presiden pertama Republik Indonesia, Bapak Bung Karno menegaskan: "bangsa ini harus dibangun dengan fokus pada character building karena character building inilah yang dibangun dengan fokus akan membuat Indonesia besar, maju, mulia" (Tanis, 2013). Hasil penelitian yang dilakukan oleh Zaman, (2019) menyatakan bahwa jika character building ini tidak dilakukan, maka bangsa ini akan menjadi bangsa kuli.

Pendidikan karakter di sekolah juga sangat terkait dengan manajemen sekolah. Manajemen yang dimaksud di sini adalah bagaimana pendidikan karakter direncanakan, dilaksanakan, dan dikendalikan dalam kegiatan- kegiatan pendidikan di sekolah secara memadai (Perdawati \& Hafulyon, 2021). Pengelolaan tersebut antara lain meliputi nilainilai yang perlu ditanamkan, muatan kurikulum, pembelajaran, penilaian, pendidik dan tenaga kependidikan, dan komponen terkait lainnya (Chandra, 2020). Hasil penelitian yang dilakukan oleh Malawi, (2016) menyatakan bahwa manajemen sekolah merupakan salah satu media yang efektif dalam pendidikan karakter di sekolah. Sekolah/madrasah selain mengimplementasikan dan melaksanakan pendidikan yang efektif dan efisien, solusi yang tepat adalah dengan melaksanakan manajemen dan meningkatkan mutu pendidikan khususnya yang berkaitan dengan pendidikan karakter yang efektif dan efisien di sekolah agar implementasi pendidikan karakter dapat optimal (Warmansyah, 2020a). 
SMA N 1 Salimpaung merupakan salah satu sekolah yang telah memperkenalkan manajemen pendidikan karakter untuk meningkatkan mutu pendidikan. SMAN 1 Salimpaung juga telah menunjukkan kualitas sekolah yang telah lulus standar nasional pendidikan dan menjadi sekolah terakreditasi A. Berdasarkan observasi lapangan pada 9 Januari 2020, penulis menemukan bahwa memiliki proses manajemen nilai karakter. Siswa SMA N 1 Salimpung dilatih dan direfleksikan dalam aktivitas sehari-hari. Penanaman nilai-nilai karakter di SMAN 1 Salimpaung dapat dilihat dalam kegiatan siswa sehari-hari. Sejak diberlakukannya kurikulum 2013, pembentukan kepribadian menjadi penilaian nilai ijazah, yakni penilaian agama dan sikap sosial. Pembentukan karakter yang digunakan di SMAN 1 Salimpaung mempengaruhi kualitas pendidikan atau sekolah di SMAN 1 Salimpaung. Hal ini terbukti dari SMAN 1 Salimpaung telah mendapatkan sertifikasi A sejak tahun 2007. SMAN 1 Salimpaung mendorong siswa yang berkarakter baik untuk diharapkan menghasilkan siswa yang cerdas, empati dan ramah.

Keberhasilan SMAN 1 Salimpaung tidak terlepas dari pengelolaan pendidikan yang ditempuh dalam mengembangkan nilai-nilai karakter. Berhasil atau tidaknya suatu sekolah tergantung pada bagaimana sekolah itu dikelola untuk meningkatkan mutu pendidikan, khususnya pendidikan pribadi.

Berdasarkan temuan di atas, maka diperlukan suatu manajemen pendidikan karakter dalam meningkatkan mutu pendidikan di satuan Sekolah Menengah Atas (SMA). Maka dari itu, peneliti tertarik untuk mengadakan penelitian yang lebih mendalam terhadap proses manajemen pendidikan karakter yang berjalan mulai dari perencanaan pendidikan karakter sampai pada evaluasi yang dilakukan di satuan dalam pelaksanaan pendidikan karakter.

\section{METODE PENELITIAN}

Jenis penelitian ini adalah penelitian kualitatif dengan pendekatan deskriptif. Jenis penelitian ini memungkinkan peneliti untuk berinteraksi langsung dengan subjek dan informan untuk memperoleh data yang akurat, terpercaya, jelas, dan lengkap. Penelitian ini bertujuan untuk menjelaskan manajemen pembentukan kepribadian untuk meningkatkan mutu pendidikan SMA N 1 Salimpaung.

Sumber data yang digunakan adalah sumber pertama: data primer diambil langsung dari kepala sekolah, direktur kurikulum, wakil presiden, guru SM AN 1 Salimpaung, dan (guru kelas, guru mata pelajaran, guru BP/BK). Data sekunder juga tersedia dalam bentuk dokumen yang berkaitan dengan fokus penelitian, seperti gambar, foto, catatan pertemuan, atau tulisan yang berkaitan dengan fokus penelitian pembentukan karakter.

Teknik pengumpulan data dalam penelitian ini adalah dengan observasi, wawancara dan dokumentasi, sedangkan teknik analisis data meliputi reduksi data (data reduction), penyajian data (data display) serta penarikan kesimpulan dan verifikasi (conclusion drawing/verivication). 


\section{HASIL DAN PEMBAHASAN}

Mengelola pembentukan karakter untuk meningkatkan mutu pendidikan di SMAN 1 Salimpaung Kabupaten Tana Data dapat dilihat dalam mengelola rencana pembentukan karakter, menyelenggarakan pembentukan karakter, melaksanakan pembentukan karakter, dan menilai pembentukan karakter, sehingga berjalan dengan baik. Berikut ini adalah bentuk manajemen pendidikan karakter yang diterapkan di SMAN1 Salimpaung Kabupaten Tanah Datar.

\section{Perencanaan Pendidikan Karakter dalam Meningkatkan Mutu Pendidikan Di SMAN 1 Salimpaung}

Rencana adalah dasar pemikiran untuk suatu tujuan dan persiapan langkahlangkah yang digunakan untuk mencapainya. Perencanaan berarti mempersiapkan segala kebutuhan, mempertimbangkan secara matang hambatan-hambatan, dan mengembangkan perwujudan kegiatan yang bertujuan untuk mencapai tujuan (Wastika, 2005). Rencana harus ada dalam semua kegiatan dan rencana tersebut dituangkan dalam konsep yang jelas. Rencana pengembangan karakter tersebut berupa kegiatan ekstrakurikuler seperti budaya sekolah dan kegiatan ekstrakurikuler serta kegiatan pembelajaran, dan memuat atau mengintegrasikan nilai-nilai karakter yang dikembangkan. Hal ini sesuai dengan yang diungkapkan (Perdawati \& Hafulyon, 2021), pada perencanaan pendidikan karakter tersebut memiliki dua makna yaitu merencanakan program dan kegiatan penanaman karakter oleh sekolah kepada peserta didik serta penanaman nilai-nilai karakter kepada para pembuat rencana itu sendiri yang memiliki keterkaitan antara unsur-unsur yang direncanakan. Unsur- unsur yang direncanakan meliputi: a) pengembangan nilai-nilai karakter pada kurikulum dan pembelajaran; b) penanaman nilai- nilai karakter pada pendidik dan tenaga kependidikan; c) penanaman nilai-nilai karakter melalui pembinaan peserta didik; d) penanaman nilai-nilai karakter melalui manajemen sarana dan prasarana pendidikan; e) penanaman nilai-nilai karakter melalui manajemen pembiayaan pendidikan.

\section{Pengorganisasian Pendidikan Karakter dalam Meningkatkan Mutu Pendidikan Di SMAN 1 Salimpaung}

Pengorganisasian merupakan cara atau kegiatan untuk mengumpulkan orangorang dan menempatkan sesuai dengan kemampuan atau bidangnya dalam pekerjaan yang sudah direncanakan (Susilawati et al., 2016). Organisasi didefinisikan oleh Devi Yana \& Asmendri (2021), sebagai kegiatan berbagi tugas di antara mereka yang terlibat dalam kerjasama pendidikan. Bahkan dalam pendidikan karakter, kegiatan tidak dapat dilakukan secara efektif dan efisien tanpa adanya organisasi.

Menurut Hambali, (2017) Dalam mewujudkan program character building dengan menyelenggarakan peningkatan mutu pendidikan, yaitu dengan berbagi tugas dan tanggung jawab dalam melakukan character building. Hasil penelitian yang dilakukan 
oleh Noprika et al., (2020) menemukan bahwa ini telah membagi peran dan tugas untuk beban kerja yang didukung semua orang, seperti peserta pelatihan.

\section{Pelaksanaan Pendidikan Karakter dalam Meningkatkan Mutu Pendidikan Di SMAN 1 Salimpaung.}

Implementasi adalah tindakan mengubah suatu rencana menjadi sarana praktis untuk mencapainya secara efektif dan efisien serta memberi nilai tambah (Turrahmi \& Amra, 2021). Penyelenggaraan pendidikan karakter merupakan kegiatan inti dari pendidikan karakter (Putri \& Mardison, 2021).

Menurut Mutakin, (2014) Penerapan pendidikan karakter di sekolah setidaknya dapat ditempuh melalui empat alternatif strategi secara terpadu. Pertama, mengintegrasikan konten pendidikan karakter yang telah dirumuskan ke dalam seluruh mata pelajaran. Kedua, mengintegrasikan pendidikan karakter ke dalam kegiatan seharihari di sekolah. Ketiga, mengintegrasikan pendidikan karakter ke dalam kegiatan yang diprogramkan atau direncanakan. Keempat, membangun komunikasi dan kerjasama antara sekolah dengan orang tua peserta didik

Implementasi pembentukan karakter di SMAN 1 Salimpaung telah berhasil, dan sudah sesuai dengan tahapan implementasi dalam rangka pengembangan nilai karakter. Proses pelaksanaan pembentukan karakter untuk meningkatkan mutu pendidikan di SMAN 1 Salimpaung:

Pertama, mengintegrasikan nilai karakter pada semua mata pelajaran. Pelaksanaan pembentukan karakter untuk meningkatkan mutu pendidikan di SMAN 1 Salimpaung adalah melalui pengintegrasian nilai-nilai karakter pada semua mata pelajaran yang termasuk dalam Rencana Pelaksanaan Pembelajaran (RPP), meliputi nilai agama, kreativitas, kemandirian dan kerjasama. hasil, gotong royong, cinta tanah air, dll.

Kedua, mengintegrasikan pendidikan karakter ke dalam kegiatan sehari-hari di sekolah. Metode pelaksanaan pendidikan karakter di SMAN 1 Salimpaung dalam mengembangkan kegiatan pengembangan diri dan budaya sekolah dalam kegiatan seharihari melalui pembiasaan rutin. Pendidikan karakter SMAN 1 Salimpaung juga dilaksanakan secara rutin agar nilai- nilai karakter melekat dalam diri pesrta didik. Pembiasaan rutin di sekolah ini meliputi saling berjabat tangan, membaca asmaul husna dan al-qur'an, shalat dhuha, shalat dzhuhur berjamaah, senyum sapa salam, bekerjasama membersihkan lingkungan sekolah dan lain- lain guna menumbuhkan nilai- nilai karakter, seperti menumbuhkan nilai religius, gotong royong dan lain-lain:

\section{Keteladanan}

di SMAN 1 Salimpaung tenaga pendidik maupun tenaga kependidikan sebagai pemimpin harus memberikan teladan atau contoh yang baik bagi peserta didik baik dalam berbicara, bersikap, berbuat atau bertindak maupun dalam berpenampilan yang mana tujuannya agar peserta didik mudah dalam menerima dan meniru perilaku baik yang dilakukan guru sehingga lama-kelamaan karakter dapat terbentuk dengan sendirinya. 


\section{Spontanitas}

kegiatan spontan yaitu kegiatan yang dilakukan secara spontan pada saat itu juga. Kegiatan ini dilakukan biasanya pada saat guru dan tenaga kependidikan yang lain di SMAN 1 Salimpaung yang mengetahui adanya perbuatan yang kurang baik dari peserta didik yang harus dikoreksi pada saat itu juga. Apabila guru mengetahui adanya perilaku dan sikap yang kurang baik maka pada saat itu juga guru melakukan koreksi sehingga peserta didik tidak akan melakukan tindakan yang tidak baik tersebut. Contoh kegiatan tersebut adalah membuang sampah tidak pada tempatnya, berteriak-teriak sehingga mengganggu pihak lain, berkelahi, melakukan bullying, memalak, berlaku tidak sopan, mencuri, berpakaian tidak sopan dan sebagainya. Contoh kegiatan spontan lain yang dilaksanakan di SMAN 1 Salimpaung adalah mengunjungi teman yang sedang terkena musibah sakit ataupun keluarganya yang meninggal, baksos ketika ada bencana alam, dan lain- lain. Kegiatan ini sangat penting untuk menumbuhkan rasa kepedulian peserta didik terhadap sesamanya.

\section{Pengkondisian}

Menurut Mujito, (2019) Pengkondisian yaitu penciptaan kondisi yang mendukung keterlaksanaan pendidikan karakter. Hasil penelitian yang dilakukan oleh Nurjanah, (2020) menemukan bahwa untuk mendukung keterlaksanaan pendidikan karakter maka sekolah harus dikondisikan sebagai pendukung kegiatan tersebut. Sekolah harus mencerminkan kehidupan sekolah yang mencerminkan nilai-nilai karakter yang diinginkan.

\section{Mengintegrasikan ke dalam program sekolah}

Pelaksanaan pendidikan karakter pada peserta didik dapat dilakukan dengan mengintegrasikan ke dalam kegiatan yang diprogramkan oleh sekolah seperti kegiatan harian. Kegiatan mingguan, kegiatan bulanan, kegiatan tahunan dan juga kegiatan ekstrakurikuler yang dapat menunjang proses pelaksanaan pendidikan karakter peserta didik.

\section{Membangun komunikasi dan kerjasama}

Salah satu faktor yang berpengaruh dalam pendidikan karakter adalah lingkungan. Aspek yang turut memberikan saham dalam terbentuknya corak pemikiran, sikap dan tingkah laku seseorang adalah faktor lingkungan dimana orang tersebut hidup (Zubaedi, 2012: 82).

Hal ini sesuai dengan pendidikan karakter dalam meningkatkan mutu pendidikan yang dilaksanakan oleh SMAN 1 Salimpaung. Dimana pihak sekolah membagun komunikasi dan kerjasama dengan orang tua peserta didik dalam hal pelaksanaan pendidikan karakter.

Berdasarkan teori diatas pengawasan pendidikan karakter di SMAN 1 Salimpaung sudah dilaksanakan dengan baik. Hal ini dilihat dari hasil wawancara, observasi dan juga dokumentasi bahwa pelaksanaan pendidikan karakter dalam meningkatkan mutu pendidikan di SMAN 1 Salimpaung adalah dengan mengintegrasikan nilai - nilai karakter pada seluruh mata pelajaran, mengintegrasikan nilai - nilai karakter pada kegiatan sehari 
hari melalui pembiasaan rutin, keteladanan, spontanitas, pengkondisian, mengintegrasikan ke dalam program sekolah dan juga membangun kerjasama dan komunikasi antara sekolah dan orang tua peserta. Dari program - program atau kegiatan yang dilaksanakan oleh SMAN 1 Salimpaung sangat berkaitan dengan penanaman nilainilai karakter yang dapat membentuk karakter peserta didik sehingga dapat meningkatkan mutu pendidikan.

Dari program atau kegiatan yang telah direncanakan sebelumnya maka akan terbentuk karakter yang kuat yang melekat dalam diri peserta didik sebagai bekal untuk melanjutkan kehidupan setelah lulus baik itu di sekolah maupun di lingkungan rumah dan masyarakat dan yang paling penting dengan terwujudnya pendidikan karakter dapat meningkatkan mutu pendidikan di SMAN 1 Salimpaung, karena untuk meningkatkan mutu pendidikan tidak hanya dalam bidang akademik saja, tetapi juga dalam bidang non akademik seperti pendidikan karakter yang diterapkan di SMAN 1 Salimpaung dengan manajemen yang baik.

\section{Terakhir, Pengawasan Pendidikan Karakter dalam Meningkatkan Mutu Pendidikan Di SMAN 1 Salimpaung}

Pengawasan atau penilaian adalah suatu kegiatan untk memperoleh informasi secara tepat, berkelanjutan tentang proses dan hasil perkembangan pendidikan karakter peserta didik (Aryani Soemitro \& Suprayitno, 2018). Pengawasan pelaksanaan pendidikan karakter dilakukan untuk memperoleh informasi, yang berkelanjutan dan menyeluruh tentang proses dan hasil yang dicapai dalam pendidikan karakter untuk dapat dilakukan evaluasi sejauh mana proses pendidikan karakter itu terlaksana.

Menurut Warmansyah (2020b) menyatakan bahwa, evaluasi merupakan upaya untuk mengetahui keadaan suatu objek dengan menggunakan alat (instrumen) tertentu dan membandingkan hasilnya dengan standar tertentu untuk memperoleh kesimpulan.

Proses pengawasan pendidikan karakter yang dilakukan SMAN 1 Salimpaung dalam meningkatkan mutu pendidikan adalah dengan cara pengawasan dilakukan oleh semua warga sekolah, baik tenaga pendidik maupun tenaga pendidikan, melakukan pengamatan atau pemantauan perilaku peserta didik dalam bentuk penskoran, melibatkan orang tua dalam pengawasan pendidikan karakter serta melakukan kunjungan rumah jika ada peserta didik yang bermasalah.

\section{KESIMPULAN}

Manajemen pendidikan karakter yang sudah berjalan dengan baik mulai dari proses perencanaan pendidikan karakter, pengorganisasian pendidikan karakter, pelaksanaan pendidikan karakter, dan pengawasan pendidikan karakter telah dilaksanakan dengan baik sehingga dapat meningkatkan mutu pendidikan di satuan dengan banyak raihan prestasi gemilang yang diperoleh oleh peserta didik maupun satuan lembaganya. Dengan mengimplementasikan manajemen pendidikan karakter tersebut 
maka, secara tidak langsung akan berdampak pada cita-cita bersama dalam pendidikan untuk mewujudkan pembentukan akhlak anak bangsa, dan diharapkan mampu menjadi dasar utama dalam menyukseskan peningkatan mutu pendidikan Indonesia. Temuan ini merupakan bahan kajian yang perlu diimplementasikan oleh satuan pendidikan mulai dari pendidikan anak usia dini sampai pendidikan tinggi dalam menerapkan pendidikan karakter pada kurikulum di satuannya agar dapat meningkatkan mutu pendidikan di satuan pendidikan masing-masing.

\section{DAFTAR PUSTAKA}

Aryani Soemitro, R. A., \& Suprayitno, H. (2018). Pemikiran Awal tentang Konsep Dasar Manajemen Aset Fasilitas. Jurnal Manejemen Aset Infrastruktur \& Fasilitas, 2(0), 1-14. https://doi.org/10.12962/j26151847.v2i0.4225

Chandra, P. (2020). Peran Pondok Pesantren dalam Membentuk Karakter Bangsa Santri di Era Disrupsi. Belajea; Jurnal Pendidikan Islam, 5(2), 243. https://doi.org/10.29240/belajea.v5i2.1497

Devi Yana, V., \& Asmendri, A. (2021). Islamic Integrated-Based School Principal Decision Making In Junior High School. Journal of Islamic Education Students (JIES), 1(1), 28. https://doi.org/10.31958/jies.v1i1.3018

Hambali. (2017). Pendidikan Adil Gender Di Pondok Pesantren ( Studi tentang Membangun Gender Awareness di Pondok Pesantren Nurul Jadid Paiton Probolinggo ). Jurnal Pedagogik, 04(02), 167-187.

Malawi, I. (2016). Implementasi Pendidikan Karakter Melalui Pembelajaran Dalam Mata Pelajaran Di Sekolah Dasar. Premiere Educandum: Jurnal Pendidikan Dasar Dan Pembelajaran, 3(01). https://doi.org/10.25273/pe.v3i01.55

Mualim, R., \& Saputra, M. F. (2021). Optimizing Online Learning during Covid 19 Pandemic in Junior High School. Journal of Islamic Education Students (JIES), 1(1), 19. https://doi.org/10.31958/jies.v1i1.3193

Mujito. (2019). Membangun Pendidikan Karakter Di Sekolah Melalui Keteladanan Guru. Jurnal Ilmiah Ilmu Pendidikan, 6(2), 47-51.

Mutakin, T. Z. (2014). Penerapan Teori Pembiasaan Dalam Pembentukan Karakter Religi Siswa Di Tingkat Sekolah Dasar. Edutech, 13(3), 361. https://doi.org/10.17509/edutech.v13i3.3089

Noprika, M., Yusro, N., \& Sagiman, S. (2020). Strategi Kepala Sekolah Dalam Peningkatan Mutu Pendidikan. Andragogi: Jurnal Pendidikan Islam Dan Manajemen Pendidikan Islam, 2(2), 224-243. https://doi.org/10.36671/andragogi.v2i2.99

Nurjanah, I. (2020). Implementasi Program Budaya Sekolah 5S (Senyum, Salam, Sapa, Sopan, Santun) dalam Menanamkan Sikap Religius Siswa di MIN 02 Kota Tangerang Selatan. Jurnal Qiro'ah, 10(1), 58-73. 
Perdawati, R. E., \& Hafulyon, H. (2021). The Effect of Administrative Services on Students' Satisfaction. Journal of Islamic Education Students (JIES), 1(1), 39. https://doi.org/10.31958/jies.v1i1.3024

Putri, S. S., \& Mardison, S. (2021). Madrasah Principal Leadership Role in Improving Teachers' Performance. Journal of Islamic Education Students (JIES), 1(1), 10. https://doi.org/10.31958/jies.v1i1.3192

Sajadi, D. (2019). Pendidikan Karakter Dalam Perspektif Islam. Tahdzib Al-Akhlaq: Jurnal Pendidikan Islam, 2(2), 16-34. https://doi.org/10.34005/tahdzib.v2i2.510

Susilawati, I., Sarbini, A., \& Setiawan, A. I. (2016). Implementasi Fungsi Manajemen dalam Pelayanan Bimbingan Manasik Haji di Kelompok Bimbingan Ibadah Haji. Tadbir: Jurnal Manajemen Dakwah, 1(2), 190-206. https://doi.org/10.15575/tadbir.v1i2.135

Suwuh, R., Pinontoan, O. R., Doda, D. V. D., Kesehatan, F., Universitas, M., \& Ratulangi, S. (2017). Gambaran Kepuasan Kerja Dan Motivasi Kerja Pada Guru Guru Di Smp Kristen Tateli Kecamatan Mandolang Kabupaten Minahasa. Kesmas, 6(4).

Tanis, H. (2013). Pentingnya Pendidikan Character Building dalam Membentuk $\begin{array}{llll}\text { Kepribadian } \quad \text { Mahasiswa. } & \text { Humaniora, }\end{array}$ https://doi.org/10.21512/humaniora.v4i2.3564

Turrahmi, M., \& Amra, A. (2021). Implementing Student Management for Children with Special Needs in Special Schools. Journal of Islamic Education Students (JIES), 1(1), 1. https://doi.org/10.31958/jies.v1i1.3017

Utami, S. W. (2019). Penerapan Pendidikan Karakter Melalui Kegiatan Kedisiplinan Siswa. Jurnal Pendidikan (Teori Dan Praktik), 4(1), 63. https://doi.org/10.26740/jp.v4n1.p63-66

Warmansyah, J. (2020a). Program Intervensi Kembali Bersekolah Anak Usia Dini Masa Pandemi Covid-19. Jurnal Obsesi : Jurnal Pendidikan Anak Usia Dini, 5(1), 743. https://doi.org/10.31004/obsesi.v5i1.573

Warmansyah, J. (2020b). Supervisi Akademik Kepala Sekolah Taman Kanak-kanak Dimasa Pandemi Covid 19. Tadbir : Jurnal Studi Manajemen Pendidikan, 4(2), 175. https://doi.org/10.29240/jsmp.v4i2.1695

Wastika, D. N. (2005). Penerapan Konsep Tri Hita Karana Dalam Perencanaan Perumahan Di Bali. Jurnal Pemukiman Natah, 3(2), 72-77.

Zaman, B. (2019). Urgensi Pendidikan Karakter Yang Sesuai Dengan Falsafah Bangsa Indonesia. AL GHAZALI , Jurnal Kajian Pendidikan Islam Dan Studi Islam, 2(1), $16-31$.

Zulhendri, Z., \& Warmansyah, J. (2020). The effectiveness of the Multisensory Method on Early Reading Ability in 6-7 Years Old Children. Jurnal Obsesi : Jurnal Pendidikan Anak Usia Dini, 5(1), 257. https://doi.org/10.31004/obsesi.v5i1.568 